\title{
Potential treatment benefits and safety of roflumilast in COPD: a systematic review and meta-analysis
}

This article was published in the following Dove Press journal:

International Journal of COPD

30 June 2016

Number of times this article has been viewed

\section{Lianfang Yuan' \\ Xuan Dai' \\ Meng Yang ${ }^{2}$ \\ Qiling Cai' \\ $\mathrm{Na}$ Shao'}

'Department of Respiration, Tianjin Hospital of ITCWM (Tianjin Nankai Hospital), ${ }^{2}$ Department of Pharmacy, Tianjin Medical University Cancer Institute and Hospital, Key Laboratory of Cancer Prevention and Therapy, Tianjin, People's Republic of China
Correspondence: Lianfang Yuan Department of Respiration, Tianjin Hospital of ITCWM (Tianjin Nankai Hospital), No 6, Changjiang Road, Nankai District, Tianjin 300I00, People's Republic of China Email alane527@sohu.com
Background: Current evidence suggests that roflumilast is efficacious in treating COPD, especially in preventing the acute exacerbation of COPD.

Objectives: This study was designed to evaluate the clinical effects and safety of roflumilast in the treatment of stable COPD using randomized clinical trial (RCT) data.

Methods: A MEDLINE, EMBASE, and Cochrane Controlled Trials Register search was carried out. RCTs reporting the treatment effects of roflumilast in COPD were identified. Relevant data were extracted and a meta-analysis was performed.

Results: A total of nine articles and 13 RCT studies were identified. Overall, $29.1 \%$ of the subjects in the roflumilast group showed evidence of exacerbation. The corresponding figure was $32.2 \%$ in the placebo group. According to pooled analysis, the use of roflumilast reduced COPD exacerbations in comparison to placebo (odds ratio $[\mathrm{OR}]=0.82,95 \%$ confidence interval $[\mathrm{CI}]=0.75-0.9$ ). The quality of life and spirometry were improved. For patients receiving baseline pre-bronchodilators, their average forced expiratory volume in the first second showed evidence of change when they took roflumilast ( $64.88 \mathrm{~mL} ; 95 \% \mathrm{CI}=54.09-75.66)$. Those who took placebo showed no evidence of change. Similar result was observed in patients receiving baseline (54.49 mL; 95\% CI =44.04-64.94). As for the safety of roflumilast treatment, the overall cumulative incidence of adverse drug reaction was $54.2 \%$ in the roflumilast group and $48.2 \%$ in the placebo group $(\mathrm{OR}=1.36,95 \% \mathrm{CI}=1.13-1.65)$. The adverse effects included diarrhea, headache, nausea, weight loss, and insomnia.

Conclusion: The efficacy of roflumilast in the prevention of acute exacerbation of COPD is obvious. Roflumilast is proved to be able to improve spirometry of COPD patients. The adverse drug reaction did not increase significantly in the roflumilast group compared with the control group. COPD patients can benefit from roflumilast therapy. However, our results are limited by the cohort design of the selected studies and the degree of heterogeneity among them; hence, more randomized trials are needed to further support this conclusion.

Keywords: COPD, roflumilast, efficacy, spirometry, adverse drug reaction, meta-analysis

\section{Background}

COPD, characterized by airflow limitation that is not fully reversible, has become one of the major health problems in the world. It is a leading cause of morbidity and mortality throughout the world, resulting in economic and social loss. Treatment of COPD is now aimed at immediately reducing the possible impact on patient's health status such as the symptoms, degree of airflow limitation, and the long-term risks, including exacerbations, comorbidities, and mortality. ${ }^{1}$ An exacerbation of COPD (AECOPD) is defined as an acute event characterized by worsening of patient's respiratory symptoms 
and requiring change of daily medication. It also causes the worsening of airflow limitation. ${ }^{2}$ For the reasons mentioned earlier, the prevention of episodes should be one of the main goals of COPD treatment. ${ }^{3}$ An ideal pharmacologic therapy can alleviate COPD symptoms, reduce the frequency and severity of exacerbation, and improve patients' health status and exercise tolerance. However, to date, the pharmacotherapeutic options for the treatment of COPD are still limited. The current treatment with long-acting muscarinic antagonists and long-acting beta-adrenoceptor agonists with or without inhaled corticosteroids has been proved to be able to produce temporary improvement in lung function and the quality of life. However, none of the existing medications has the efficacy to modify the long-term decline of a patient's lung function. ${ }^{4}$ Based on many early-stage research studies, we understand that there is a direct relationship between the severity of the disease and the intensity of the inflammatory responses. ${ }^{5}$ Hence, decreasing the degree of inflammation will have a significant benefit in terms of AECOPD reduction. Phosphodiesterase inhibition is an old concept in the treatment of COPD that was introduced by Hirsch et al in 1922. ${ }^{6}$ However, the narrow dose range and cardiovascular and gastrointestinal side effects limit the application of the prototypic nonselective phosphodiesterase inhibitors, such as aminophylline and theophylline. In the past decade, eleven different types have been identified. Each type has different tissue distribution and substrate specificities. ${ }^{7}$ The presence of the phosphodiesterase 4 (PDE4) isoenzyme in many of the cell types implicated in COPD will make it a promising target for disease-modifying therapy, given the decline in lung function was closely related to chronic airway inflammation and mucus hypersecretion. ${ }^{8}$ Roflumilast, a phosphide stressor 4 inhibitor, has a high affinity to PDE4. Several clinical studies ${ }^{9-16}$ have demonstrated that roflumilast improves lung function, regardless of concomitant COPD treatment, and reduces the risk of exacerbations. These studies convey inconclusive results. To evaluate the potential benefits and safety of roflumilast in COPD treatment, a literature search was conducted to identify all randomized clinical trials (RCTs) involving the use of roflumilast in COPD.

\section{Methods}

\section{Identification and selection of papers}

A systematic review and meta-analysis were performed according to the recently published recommendations and checklists of the Preferred Reporting Items for Systematic Reviews and Meta-Analyses statement. We decided a priori to examine the published literature that evaluates the effects of roflumilast therapy on outcomes in COPD conducted on MEDLINE (inception-October 2015), EMBASE (inceptionOctober 2015), and the Cochrane Collaboration and the Cochrane Register of Controlled Trials for relevant trials.

The search key terms were used to identify citations relevant to "roflumilast". The following search terms were used to identify citations relevant to COPD: "COPD", "emphysema", "chronic bronchitis", "chronic obstructive pulmonary/respiratory/lung/airways disease", "chronic airflow obstruction", and "airway/lung/pulmonary inflammation". The search was limited to articles published in English and Chinese and studies conducted on human beings. We identified additional studies by searching the bibliographies of retrieved articles. The reference lists of identified publications were also searched. The search strategy was discussed and agreed upon by all the authors, and the advice was sought from a medical librarian experienced in medical informatics. Randomized, double-blinded or single-blinded, placebo-controlled studies were included. Studies in which outcomes of treatment with roflumilast were examined for a subgroup of subjects with COPD or obstructive pulmonary function were also included. Non-RCTs were excluded, given the fact that RCTs represent the most robust level of efficacy evidence, especially for outcomes reported by patients. Trials that involved mixed populations (eg, people with asthma and COPD) were excluded, unless separate data were reported for COPD patients. Only articles reporting original data were retained; abstracts, editorials, and letters were excluded.

\section{A review of studies}

All duplicate citations of the initial database were eliminated. Two independent reviewers performed the literature search by screening these citations by title and abstract, identified all studies for full review to confirm eligibility, and selected independent studies for their inclusion in the systematic review. Disagreement between these reviewers was resolved by a review of the study by a third person, and the decision to include and exclude a study was reached by consensus.

\section{Data extraction}

We extracted data regarding the number of objectives, study design, inclusion and exclusion criteria for participants, basic information, details on roflumilast treatment, duration of follow-up, and outcome measurements (ie, exacerbation, pulmonary function, adverse event, etc). Particular attention was given to the inclusion or exclusion of patients with asthma. Details of roflumilast treatment included different dosages, duration of treatment, and adherence to treatment. 


\section{Assessment of methodological quality of included studies}

Study quality for the RCT was assessed for evidence of concealed randomization, similarity of the randomized groups at baseline, standardization of nonintervention treatment strategies between treatment groups, blinding of patients and investigators, number of crossovers, intention-to-treat analysis, follow-up to the defined outcome, and generalizability of the conclusions of the trial to other populations.

\section{Analysis method}

All quantitative data analysis was performed by means of Review Manager Version 5.1. Where it was possible, odds ratios (ORs) were used to compute pooled ORs for analysis. In studies not quoting the ORs or CIs, these were estimated by using the following data: the total number of events and the total number of patients in each group. Heterogeneity between studies was assessed by the $Q$ test and $I^{2}$ statistic. ${ }^{18}$ When a significant $Q$ test $\left(P<0.10\right.$ or $\left.I^{2}>50 \%\right)$ indicated heterogeneity across studies, the random-effects model was used for meta-analysis or else the fixed-effects model was used.

\section{Results}

\section{Eligible studies}

The initial search strategy yielded 261 articles (Figure 1). After screening titles and abstracts, 12 articles that included potentially relevant studies were identified and chosen for full review and three of them were excluded from further

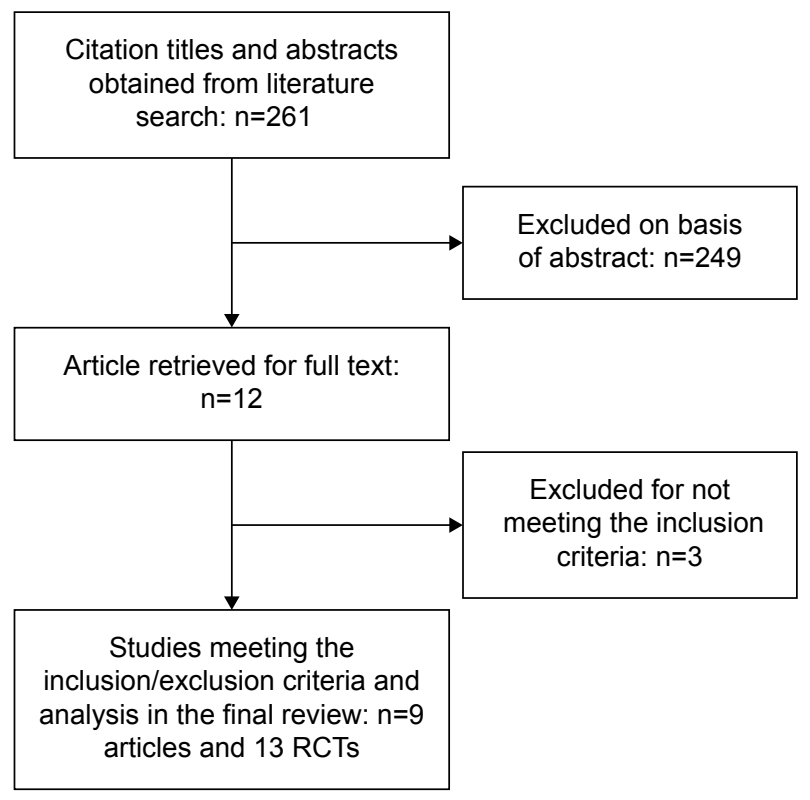

Figure I Flowchart for identification of studies included in the meta-analysis. Abbreviation: RCT, randomized clinical trial. analysis. In the end, a total of nine articles and $13 \mathrm{RCT}$ studies met the inclusion criteria for this meta-analysis. ${ }^{9-17}$ The baseline characteristics of the selected studies are shown in Table 1. Pooled data about 13,600 patients were available for analysis, with 7,206 patients in the roflumilast group and 6,394 in the placebo group. The duration of treatment ranged from 12 weeks to 52 weeks.

\section{Quality assessment and publication bias}

All studies had clearly defined eligibility criteria, therapies, and reasons for patient exclusion. Furthermore, no evidence of publication bias was found from funnel plots and associated statistics.

\section{COPD exacerbations}

The effect of roflumilast on the incidence of acute COPD exacerbations has been discussed in seven articles and eleven RCT studies. ${ }^{9-15}$ The overall cumulative incidence of exacerbations was $29.1 \%$ in the roflumilast group and $32.2 \%$ in the placebo group. Pooled analysis showed that the use of roflumilast significantly reduced COPD exacerbations compared to placebo $(\mathrm{OR}=0.82,95 \%$ confidence interval $[\mathrm{CI}]=0.75-0.9$; Figure 2).

\section{Spirometric testing}

The effect of roflumilast on the spirometric change in forced expiratory volume in the first second $\left(\mathrm{FEV}_{1}\right)$ from baseline prebronchodilator was studied in eight articles and $12 \mathrm{RCT}$ studies. ${ }^{9-16}$ The mean $\mathrm{FEV}_{1}$ change from baseline of patients who received roflumilast compared with placebo was $64.88 \mathrm{~mL}$; 95\% CI =54.09-75.66 (Figure 3). The effect of roflumilast on the spirometric change in $\mathrm{FEV}_{1}$ from baseline postbronchodilator was studied in eight articles and $12 \mathrm{RCT}$ studies. ${ }^{9-14,16,17}$ The mean $\mathrm{FEV}_{1}$ changed from baseline of patients who received roflumilast compared with placebo was $54.49 \mathrm{~mL}$; 95\% CI =44.04-64.94 (Figure 4).

\section{Safety}

Adverse events were observed in seven articles and nine RCT studies during follow-up comparisons between the roflumilast group and the placebo group..$^{9-14,16}$ Statistically adverse events that were considered to be related to treatment did not significantly differ between the roflumilast group and the placebo group. The overall cumulative incidence of adverse drug reaction (ADR) was $54.2 \%$ in the roflumilast group and $48.2 \%$ in the placebo group $(\mathrm{OR}=1.36,95 \% \mathrm{CI}=1.13-1.65$; Figure 5). There are a few notable limitations to the results mentioned earlier, and the adverse events here included the COPD 
Table I Characteristics of included studies

\begin{tabular}{|c|c|c|c|c|c|c|}
\hline Study & Design & $\begin{array}{l}\text { Duration } \\
\text { (weeks) }\end{array}$ & $\begin{array}{l}\text { Grade }\left(F E V_{1} \% /\right. \\
\text { predict }) /(\text { FEV } / \text { FVC) }\end{array}$ & Dosage & Patient number & Jadad score \\
\hline \multirow[t]{2}{*}{ Rabe et $\mathrm{al}^{9}(\mathrm{~L})$} & $\mathrm{R}, \mathrm{DB}$ & 24 & $30 \%-80 \%$ & RO $250 \mathrm{mg} / \mathrm{d}$ & 578 & 5 \\
\hline & & & $<70 \%$ & Placebo & 280 & \\
\hline \multirow[t]{2}{*}{ Rabe et $\mathrm{al}^{9}(\mathrm{H})$} & $R, D B$ & 24 & $30 \%-80 \%$ & RO $500 \mathrm{mg} / \mathrm{d}$ & 555 & 5 \\
\hline & & & $<70 \%$ & Placebo & 280 & \\
\hline \multirow[t]{2}{*}{ Calverley et al ${ }^{10}$} & $\mathrm{R}, \mathrm{DB}$ & 52 & $<50 \%$ & RO $500 \mathrm{mg} / \mathrm{d}$ & 760 & 6 \\
\hline & & & $<70 \%$ & Placebo & 753 & \\
\hline \multirow[t]{2}{*}{ Calverley et al" (M2-124) } & $\mathrm{R}, \mathrm{DB}$ & 52 & $<50 \%$ & RO $500 \mathrm{mg} / \mathrm{d}$ & 765 & 6 \\
\hline & & & $<70 \%$ & Placebo & 758 & \\
\hline \multirow[t]{2}{*}{ Claverley et al" (M2-125) } & $\mathrm{R}, \mathrm{DB}$ & 52 & $<50 \%$ & RO $500 \mathrm{mg} / \mathrm{d}$ & 772 & 6 \\
\hline & & & $<70 \%$ & Placebo & 796 & \\
\hline \multirow[t]{2}{*}{ Fabbri et al ${ }^{12}$ (M2-I $\left.27[\mathrm{~S}]\right)$} & $\mathrm{R}, \mathrm{DB}$ & 24 & $40 \%-70 \%$ & RO $500 \mathrm{mg} / \mathrm{d}$ & 466 & 6 \\
\hline & & & $<70 \%$ & Placebo & 467 & \\
\hline \multirow[t]{2}{*}{ Fabbri et al ${ }^{12}$ (M2-I28 [T]) } & $\mathrm{R}, \mathrm{DB}$ & 24 & $40 \%-70 \%$ & RO $500 \mathrm{mg} / \mathrm{d}$ & 371 & 6 \\
\hline & & & $<70 \%$ & Placebo & 372 & \\
\hline \multirow[t]{2}{*}{ Rennard et $\mathrm{al}^{13}$ (M2-III) } & $\mathrm{R}, \mathrm{DB}$ & 52 & $<50 \%$ & RO $500 \mathrm{mg} / \mathrm{d}$ & 567 & 6 \\
\hline & & & $<70 \%$ & Placebo & 606 & \\
\hline \multirow[t]{2}{*}{ Rennard et al ${ }^{13}$ (M2-I I2) } & $\mathrm{R}, \mathrm{DB}$ & 52 & $<50 \%$ & RO $500 \mathrm{mg} / \mathrm{d}$ & 760 & 6 \\
\hline & & & $<70 \%$ & Placebo & 753 & \\
\hline \multirow[t]{2}{*}{ Lee et $\mathrm{al}^{14}$} & $\mathrm{R}, \mathrm{DB}$ & 12 & $30 \%-80 \%$ & RO $500 \mathrm{mg} / \mathrm{d}$ & 203 & 6 \\
\hline & & & $<70 \%$ & Placebo & 207 & \\
\hline \multirow[t]{2}{*}{ O’Donnell et al ${ }^{15}$} & $R, D B$ & 12 & $30 \%-80 \%$ & RO $500 \mathrm{mg} / \mathrm{d}$ & 127 & 6 \\
\hline & & & $<70 \%$ & Placebo & 123 & \\
\hline \multirow[t]{2}{*}{ Zheng et al ${ }^{16}$} & $\mathrm{R}, \mathrm{DB}$ & 24 & $<50 \%$ & RO $500 \mathrm{mg} / \mathrm{d}$ & 313 & 6 \\
\hline & & & $<70 \%$ & Placebo & 313 & \\
\hline \multirow[t]{2}{*}{ Martinez et al ${ }^{17}$} & $R, D B$ & 52 & $<50 \%$ & RO $500 \mathrm{mg} / \mathrm{d}$ & 969 & 6 \\
\hline & & & $<70 \%$ & Placebo & 966 & \\
\hline
\end{tabular}

Note: Items in brackets in the Study column are code names within the trial.

Abbreviations: $\mathrm{FEV}_{1}$, forced expiratory volume in the first second; FVC, forced vital capacity; L, low; R, randomized; DB, double blind; RO, roflumilast; $\mathrm{H}$, high; $\mathrm{S}$, salmeterol; T, tiotropium.

exacerbation. Compared with placebo, most of the roflumilast treatment-related events affected the gastrointestinal tract and nervous system. The most common adverse event reported in the treatment was diarrhea $(7.2 \%$ and $1.8 \%$ of patients in the roflumilast and placebo groups, respectively; OR $=4.49,95 \%$
$\mathrm{CI}=3.16-6.38$; Table 2$)$, nausea $(3.6 \%$ and $1.1 \%$ of patients in the roflumilast and placebo groups, respectively; $\mathrm{OR}=3.82$, $95 \% \mathrm{CI}=2.16-4.53$; Table 2 ), and nasopharyngitis ( $7.6 \%$ and $5.6 \%$ of patients in the roflumilast and placebo groups, respectively; $\mathrm{OR}=0.96,95 \% \mathrm{CI}=0.83-1.12$; Table 2).

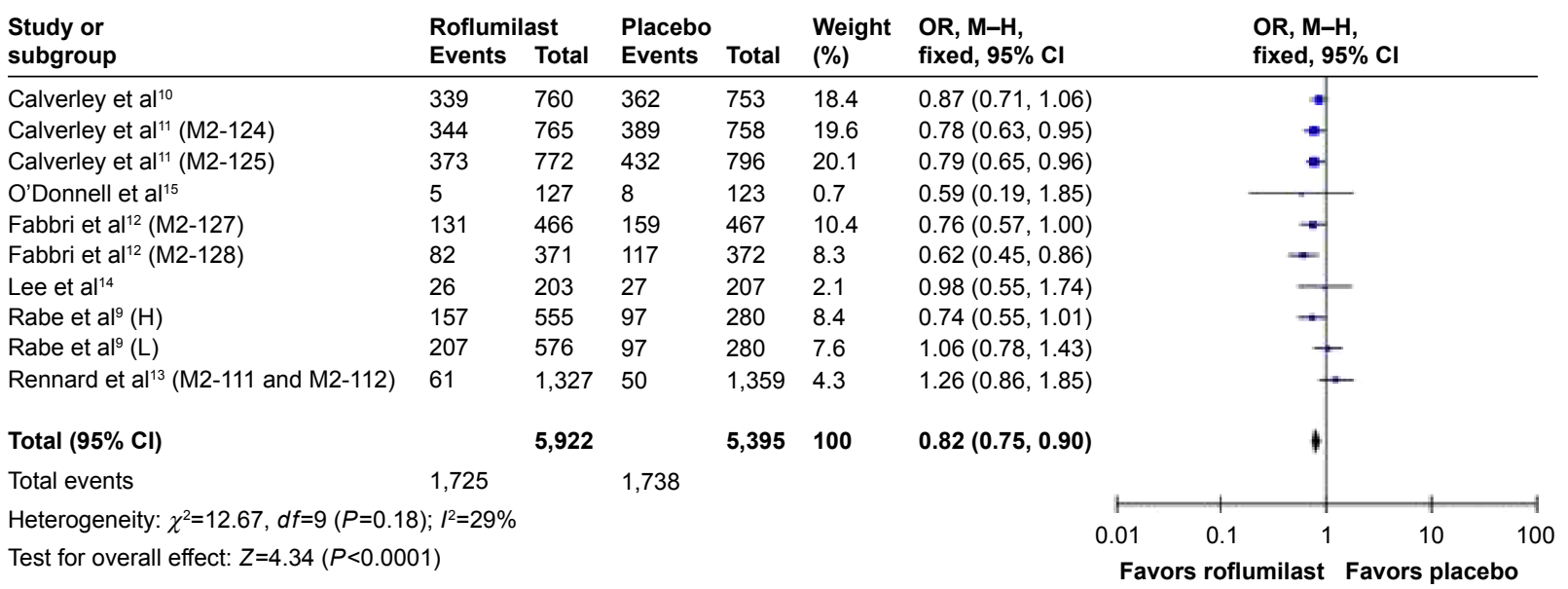

Figure 2 Pooled OR for COPD-related exacerbations (with $95 \% \mathrm{Cl}$ ) of eligible studies comparing roflumilast with placebo.

Note: Items in brackets in the Study column are code names within the trial.

Abbreviations: OR, odds ratio; $\mathrm{Cl}$, confidence interval; $\mathrm{M}-\mathrm{H}$, Mantel-Haenszel; $\mathrm{H}$, high; L, low. 


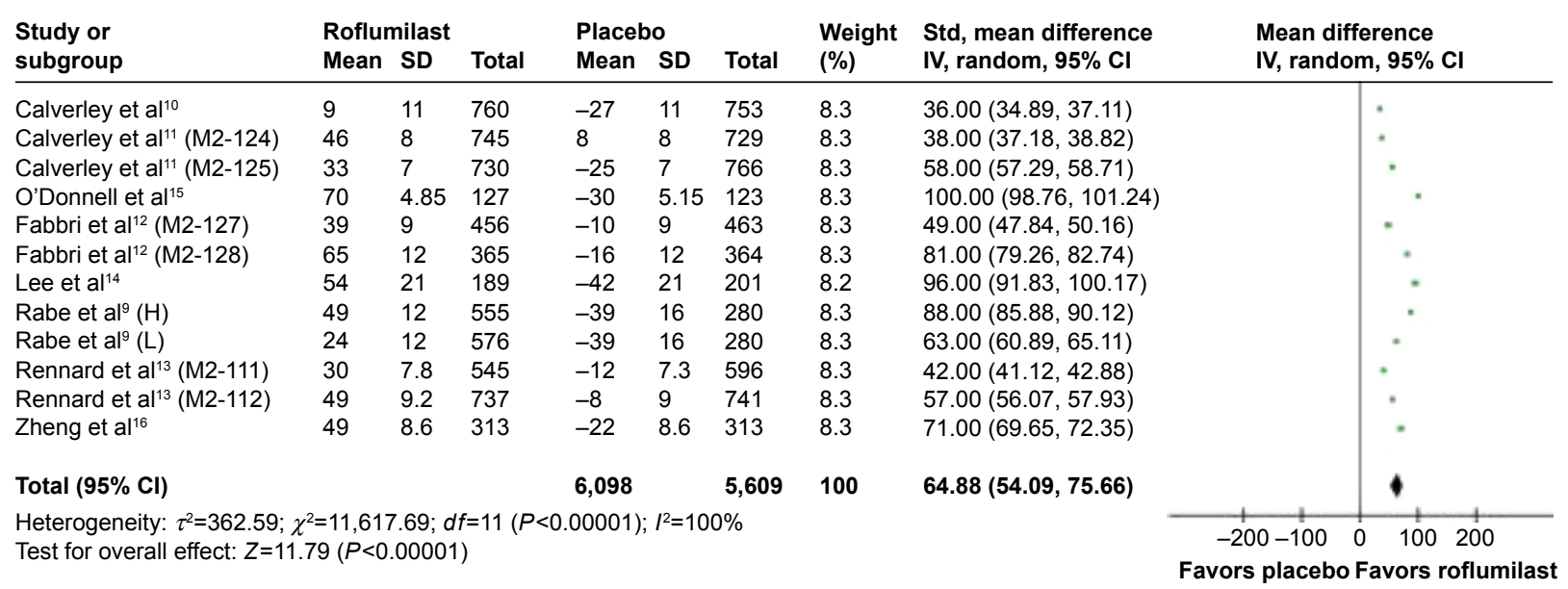

Figure 3 Pooled mean change of $\mathrm{FEV}$, from baseline prebronchodilator (with $95 \% \mathrm{Cl}$ ) of eligible studies comparing roflumilast with placebo.

Note: Items in brackets in the Study column are code names within the trial.

Abbreviations: $\mathrm{FEV}_{1}$, forced expiratory volume in the first second; Cl, confidence interval; Std, standard; IV, instrumental variable; H, high; L, low; SD, standard deviation.

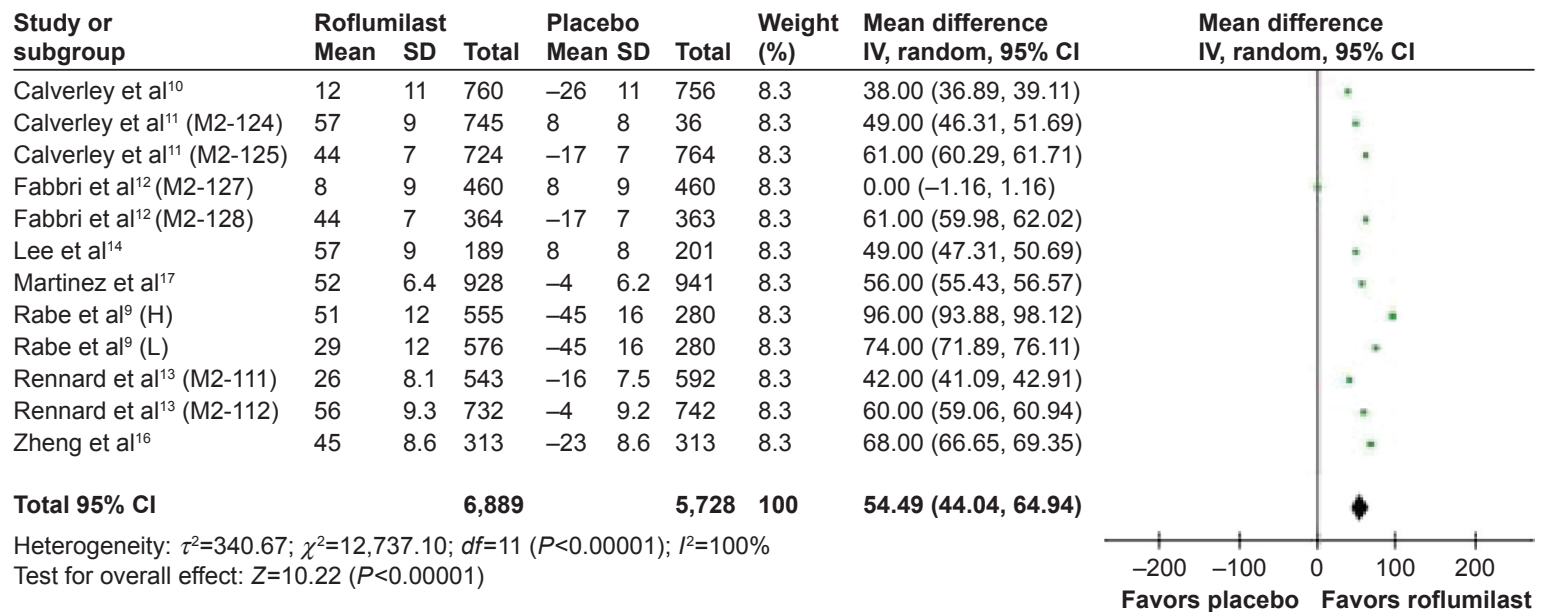

Figure 4 Pooled mean change of $\mathrm{FEV}$, from baseline postbronchodilator (with $95 \% \mathrm{Cl}$ ) of eligible studies comparing roflumilast with placebo.

Note: Items in brackets in the Study column are code names within the trial.

Abbreviations: $\mathrm{FEV}_{1}$, forced expiratory volume in the first second; $\mathrm{Cl}$, confidence interval; IV, instrumental variable; $\mathrm{H}$, high; $\mathrm{L}$, low; SD, standard deviation.

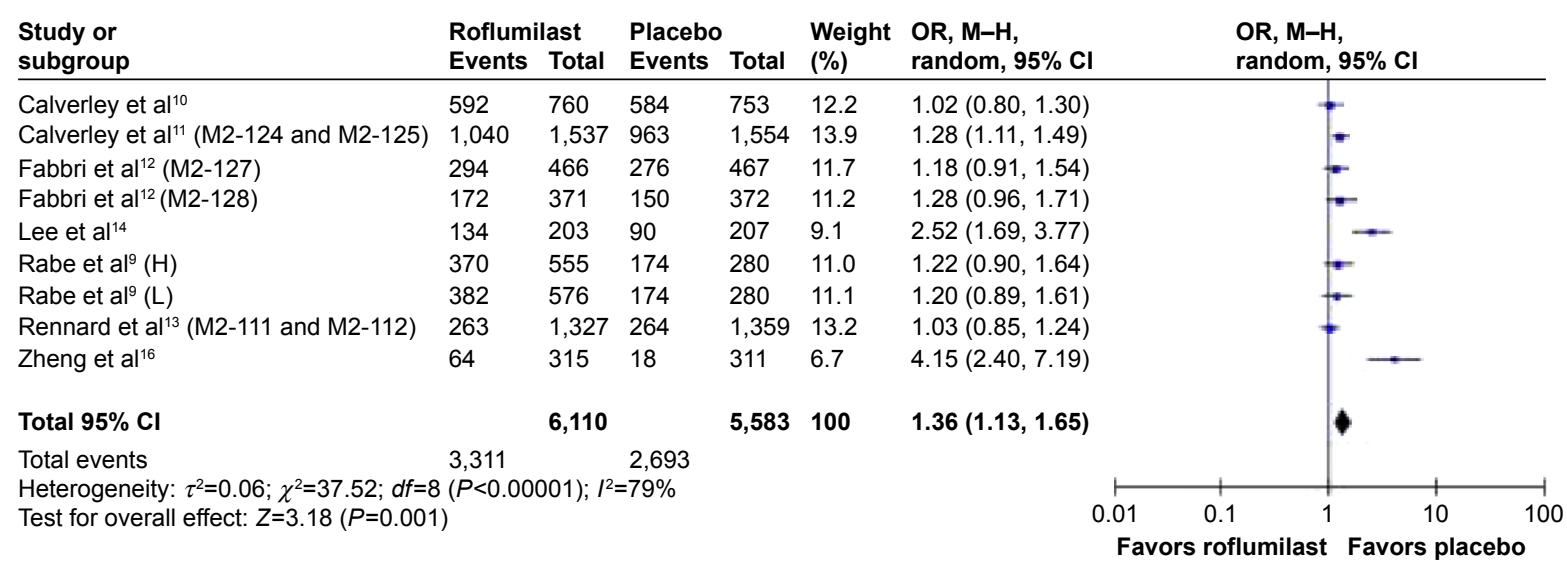

Figure 5 Pooled OR for adverse event (with $95 \% \mathrm{Cl}$ ) of eligible studies comparing roflumilast with placebo.

Note: Items in brackets in the Study column are code names within the trial.

Abbreviations: OR, odds ratio; $\mathrm{Cl}$, confidence interval; $\mathrm{M}-\mathrm{H}$, Mantel-Haenszel; $\mathrm{H}$, high; L, low. 
Table 2 Analysis of adverse event

\begin{tabular}{|c|c|c|c|c|c|c|c|}
\hline \multirow[t]{3}{*}{ Adverse event } & \multicolumn{6}{|c|}{ Pool study population } & \multirow[t]{3}{*}{ OR (95\% Cl) } \\
\hline & \multicolumn{3}{|c|}{ Roflumilast group } & \multicolumn{3}{|c|}{ Placebo group } & \\
\hline & Event & Total & Rate (\%) & Event & Total & Rate (\%) & \\
\hline Diarrhea & 520 & 7,218 & 7.2 & 117 & 6,381 & 1.8 & $4.49(3.16-6.38)$ \\
\hline Nausea & 250 & 7,015 & 3.6 & 67 & 6,174 & 1.1 & $3.82(2.16-4.53)$ \\
\hline Weight loss & 335 & 5,313 & 6.3 & 85 & 5,348 & 1.5 & $4.07(3.13-5.30)$ \\
\hline Nasopharyngitis & 524 & 6,903 & 7.6 & 344 & 6,070 & 5.6 & $0.96(0.83-1.12)$ \\
\hline Headache & 190 & 6,087 & 3.1 & 76 & 6,101 & 1.2 & $2.4(1.83-3.15)$ \\
\hline
\end{tabular}

\section{Discussion}

Roflumilast is a selective PDE4 inhibitor with a proven role in preventing chronic airway inflammation, primarily via its anti-inflammatory effect. It is postulated to be beneficial for patients with chronic airway inflammation disease. Functional consequences of inhibiting PDE4 (the major hydrolase of cyclic adenosine monophosphate (cAMP) in the inflammatory cell) have consistently shown ability to increase intracellular cAMP and to downregulate the activity of several proinflammatory and structural cells such as macrophages, lymphocytes, and airway epithelial cells. Involved in the pathophysiology of COPD, it can suppress proinflammatory cell recruitment and cytokine and chemokine production and prevent emphysematous changes in the lung. ${ }^{11,12}$ The primary function of roflumilast lies in the fact that it can mitigate inflammation by inhibiting the breakdown of intracellular cAMP. It has no direct bronchodilator activity, although it has been proved to be able to improve $\mathrm{FEV}_{1}$ in patients treated with bronchodilators such as long-acting beta-adrenoceptor agonist and long-acting muscarinic antagonist. Several clinical studies ${ }^{9-16}$ have shown that roflumilast can reduce moderate and severe exacerbations.

This study used RCT data to evaluate the clinical effects and safety of roflumilast in the treatment of stable COPD to determine implications for future studies. We identified a total of nine articles and 13 RCT studies that suggest that patients treated with roflumilast benefited when it came to COPD exacerbations, COPD hospitalizations, lung function, and quality of life with only a few adverse effects. First, roflumilast can prevent the exacerbation of COPD. The overall cumulative incidence of exacerbation was $29.1 \%$ in the roflumilast group and $32.2 \%$ in the placebo group $(\mathrm{OR}=0.82$, $95 \% \mathrm{CI}=0.75-0.9$ ). Second, it can improve lung function in terms of both $\mathrm{FEV}_{1}$ and forced vital capacity. The mean $\mathrm{FEV}_{1}$ witnessed a change in baseline pre-bronchodilator of patients who received roflumilast compared with the placebo group (64.88 $\mathrm{mL}$; 95\% CI $=54.09-75.66)$. It is the same for the baseline of patients who received roflumilast $(54.49 \mathrm{~mL} ; 95 \%$
$\mathrm{CI}=44.04-64.94)$. As for its safety, the overall cumulative incidence of ADR was $54.2 \%$ in the roflumilast group and $48.2 \%$ in the placebo group $(\mathrm{OR}=1.36,95 \% \mathrm{CI}=1.13-1.65)$. Most of the adverse events affected the gastrointestinal tract and nervous system. The most common adverse events reported in the treatment were diarrhea $7.2 \%$ in the roflumilast group and $1.8 \%$ in the placebo group; $\mathrm{OR}=4.49,95 \%$ $\mathrm{CI}=3.16-6.38)$, nausea (3.6\% in the roflumilast group and $1.1 \%$ in the placebo group; $\mathrm{OR}=3.82,95 \% \mathrm{CI}=2.16-4.53$ ), and nasopharyngitis (7.6\% in the roflumilast group and $5.6 \%$ in the placebo group; $\mathrm{OR}=0.96,95 \% \mathrm{CI}=0.83-1.12$ ). Interestingly, the rate of nasopharyngitis in both groups was high. Our opinion about this is that the adverse effect is related to the combined use of inhaled corticosteroids rather than that of roflumilast. Roflumilast should also be used with caution in patients with depression. Roflumilast and theophylline should not be given together in case of drug overdose. In summary, our analysis suggests that the efficacy of roflumilast in preventing acute exacerbation of COPD is obvious. Roflumilast has been proved to be able to improve spirometry of COPD patients. The ADR does not increase significantly in the roflumilast group compared with the control group. COPD patients can benefit in the treatment of roflumilast therapy.

However, the current systematic review has some limitations. Initially, we chose not to use stringent selection criteria for we recognizes that currently there is little evidence from research in this area. Heterogeneity across the selected studies is inevitable when it comes to study design, interventions, and outcomes assessed. Second, we only included papers in English and Chinese, thereby possibly limiting the scope of the included studies. As in any systematic review, publication bias is a concern, which will possibly lead to the overestimation of the associations of roflumilast treatment with favorable outcomes in COPD. Therefore, despite the encouraging results, all studies reported to date have limitations and should be considered. The true effect of roflumilast treatment on COPD remains to be elucidated, as does 
the dose and duration required to achieve any such effect. So more carefully designed RCTs need to be performed to obtain sufficient evidence to justify a clinical indication for roflumilast in COPD treatment.

\section{Conclusion}

The efficacy of roflumilast in the prevention of acute exacerbation of COPD is obvious. Roflumilast is proved to be able to improve spirometry of COPD patients. The adverse drug reaction did not increase significantly in the roflumilast group compared with the control group. COPD patients can benefit from roflumilast therapy. However, our results are limited by the cohort design of the selected studies and the degree of heterogeneity among them; hence, more randomized trials are needed to further support this conclusion.

\section{Disclosure}

The authors report no conflicts of interest in this work.

\section{References}

1. GOLD COPD [homepage on the Internet]. Global Strategy for the Diagnosis Management and Prevention of COPD (updated 2015) GOLD, the Pocket Guide (updated 2015). 2015. Available from: http://www. goldcopd.org. Accessed May 28, 2016.

2. Soler-Cataluña JJ, Martínez-García MA, Román Sánchez P, Salcedo E, Navarro M, Ochando R. Severe acute exacerbations and mortality in patients with chronic obstructive pulmonary disease. Thorax. 2005;60: 925-931.

3. Miravitlles M, Anzueto A, Legnani D, et al. Patient's perception of exacerbations of COPD: the PERCEIVE study. Respir Med. 2007;101: 453-460.

4. Celli B, Vestbo J, Jenkins CR, et al. Gender differences in mortality and clinical expressions of patients with COPD: the TORCH experience. Am J Respir Crit Care Med. 2010;183(3):317-322.

5. Curtis JL, Freeman CM, Hogg JC. The immune-pathogenesis of chronic obstructive pulmonary disease: insights from recent research. Proc Am Thorac Soc. 2007;4:512-521.
6. Diamant Z, Boot JD, Virchow JC. Summing up 100 years of asthma. Respir Med. 2007;101:378-388.

7. Boswell-Smith V, Spina D, Page CP. Phosphodiesterase inhibitors. Br J Pharmacol. 2006;147:S252-S257.

8. Vestbo J, Prescott E, Lange P. Association of chronic mucus hypersecretion with FEV decline and chronic obstructive pulmonary disease morbidity. Copenhagen City Heart Study Group. Am J Respir Crit Care Med. 1996;153:1530-1535.

9. Rabe KF, Bateman ED, O'Donnell D, Witte S, Bredenbroker D, Bethke TD. Roflumilast - an oral anti-inflammatory treatment for chronic obstructive pulmonary disease: a randomised controlled trial. Lancet. 2005;366:563-571.

10. Calverley PM, Sanchez-Toril F, McIvor A, Teichmann P, Bredenbroeker D, Fabbri LM. Effect of 1-year treatment with roflumilast in severe chronic obstructive pulmonary disease. Am J Respir Crit Care Med. 2007;176:154-161.

11. Calverley PM, Rabe KF, Goehring UM, et al; M2-124 and M2-125 Study Groups. Roflumilast in symptomatic chronic obstructive pulmonary disease: two randomised clinical trials. Lancet. 2009;374:685-694.

12. Fabbri LM, Calverley PM, Izquierdo-Alonso JL, et al. Roflumilast in moderate-to-severe chronic obstructive pulmonary disease treated with long-acting bronchodilators: two randomised clinical trials. Lancet. 2009;374:695-703.

13. Rennard SI, Calverley PM, Goehring UM, Bredenbroker D, Martinez FJ. Reduction of exacerbations by the PDE4 inhibitor roflumilast the importance of defining different subsets of patients with COPD. Respir Res. 2011;12:18.

14. Lee SD, Hui DS, Mahayiddin AA, et al. Roflumilast in Asian patients with COPD: a randomized placebo-controlled trial. Respirology. 2011; 16:1249-1257.

15. O'Donnell DE, Bredenbröker D, Brose M, Webb KA. Physiological effects of roflumilast at rest and during exercise in COPD. Eur Respir J. 2012;39:1104-1112

16. Zheng J, Yang J, Zhou X, et al. Roflumilast for the treatment of COPD in an Asian population: a randomized, double-blind, parallel group study. Chest. 2014;145(1):44-52.

17. Martinez FJ, Calverley PM, Goehring UM, Brose M, Fabbri LM, Rabe KF. Effect of roflumilast on exacerbations in patients with severe chronic obstructive pulmonary disease uncontrolled by combination therapy (REACT): a multicentre randomised controlled trial. Lancet. 2015;385:857-866.

18. Higgins JP, Thompson SG. Quantifying heterogeneity in a metaanalysis. Stat Med. 2002;21:1539-1558
International Journal of COPD

\section{Publish your work in this journal}

The International Journal of COPD is an international, peer-reviewed journal of therapeutics and pharmacology focusing on concise rapid reporting of clinical studies and reviews in COPD. Special focus is given to the pathophysiological processes underlying the disease, intervention programs, patient focused education, and self management protocols.

\section{Dovepress}

This journal is indexed on PubMed Central, MedLine and CAS. The manuscript management system is completely online and includes a very quick and fair peer-review system, which is all easy to use. Visit http://www.dovepress.com/testimonials.php to read real quotes from published authors. 